\title{
REFLEXÕES SOBRE O PAPEL DAS FAKE NEWS NA DEMOCRACIA BRASILEIRA
}

\author{
Joel Cezar Bonin ${ }^{1}$ \\ Suzana Miranda Portes ${ }^{2}$ \\ Angela Faoro ${ }^{3}$ \\ Recebido em 05/08/2021 \\ Aceito em 11/09/2021
}

\begin{abstract}
RESUMO
Nos últimos anos, ganhou destaque a questão da manipulação de notícias inverídicas em cadeia nacional, nas redes sociais especialmente, para fins políticos, com o intento de prejudicar ou favorecer pessoas públicas. No Brasil, ocorre uma investigação do Supremo Tribunal Federal nominada por inquérito das Fake News desde 2019. O inquérito visa compreender de que modo e com qual alcance essa prática influenciou as eleições presidenciais de 2018 e em que medida a prática das fake news acabou por perpetuar uma visão deturpada da vida pública de pessoas ligadas ao universo público brasileiro. Assim, questiona-se, por meio deste artigo, se estas formas de comunicação estariam ofendendo princípios democráticos com o intuito deliberado de macular a imagem de algumas pessoas e de enaltecer outras, com base em informações inventadas e veiculadas por meio das redes sociais. Para isso, tomou-se como referência documentos públicos do inquérito em trâmite, notícias falsas encontradas na internet e principalmente leituras sobre o tema a partir de uma revisão bibliográfica e documental. Ao final, ao se falar sobre a disseminação de notícias fraudulentas, reflete-se sobre a educação digital e a necessária verificação de notícias em busca de um jornalismo intelectual de qualidade que combata a informação desvirtuada, sustentando o sistema democrático e não distorcendoo.
\end{abstract}

PALAVRAS-CHAVE: Fake news, mídias, eleições, democracia, Supremo Tribunal Federal.

\section{REFLECTIONS ON THE ROLE OF FAKE NEWS IN BRAZILIAN DEMOCRACY}

\begin{abstract}
In recent years, the issue of manipulation of untrue news on national channels, on social networks, especially for political purposes, with the intention of harming or favoring public persons, has gained prominence. In Brazil, there is an investigation by the Supreme Court named Fake News inquiry, since 2019. The inquiry aims to understand how and with what reach this practice influenced the 2018 presidential elections, and to what extent the practice of fake news ended up perpetuating a distorted view of the public life of people connected to the Brazilian public universe. Thus, it is questioned, through this article, whether these forms of communication would be offending democratic principles
\end{abstract}

\footnotetext{
${ }^{1}$ Doutor em Filosofia pela Pontifícia Universidade Católica do Paraná (2020). Atua como professor no Mestrado Acadêmico em Desenvolvimento e Sociedade (PPGDS), na linha de pesquisa "Sociedade, Cidadania e Segurança" (2020) e no Mestrado Profissional em Educação Básica, na linha de pesquisa "Políticas Públicas e Gestão da Educação" (2019). Tem experiência na área de Filosofia, com ênfase em Filosofia Política Moderna e Contemporânea, atuando principalmente nos seguintes temas: educação, filosofia, sociologia, antropologia, sustentabilidade, ética, cidadania e política.

${ }^{2}$ Possui graduação em Direito pela Universidade do Oeste de Santa Catarina (2010).

${ }^{3}$ Possui graduação em Comunicação Social pela Universidade do Sul de Santa Catarina (2008).
} 
with the deliberate intention of tarnishing the image of some people and praising others, based on invented information and conveyed through social networks. For this, public documents of the ongoing investigation, false news found on the internet, and mainly readings on the subject from a bibliographical and documental review were taken as reference. In the end, when talking about the dissemination of fraudulent news, one reflects on digital education and the necessary verification of news in search of quality intellectual journalism that fights distorted information, sustaining the democratic system and not distorting it.

Keywords: Fake news, media, elections, democracy, Supreme Court.

\section{Introdução}

Quando pensamos em fake news, percebemos que o termo se tornou popular no Brasil desde o último pleito eleitoral de 2018, assunto recorrente nas mídias sociais, campanhas eleitorais e pesquisas eleitorais. Antes disso, nunca haviam sido, no Brasil, utilizadas as mídias sociais massivamente em campanhas eleitorais, pois era mais comum a realização de campanhas por meio da televisão, do rádio e outros meios comuns.

Diante disso, a Folha de São Paulo ${ }^{4}$ veiculou, em primeira mão, uma matéria sobre uma notícia-bomba movida a fake news, em 18 de outubro de 2018: um conjunto de empresários teria contratado empresas de comunicação virtual para enviar falsas notícias por meio do Facebook e do Whatsapp, contendo ataques contra candidatos da oposição, favorecendo o candidato apoiado, durante a campanha eleitoral do mesmo ano. Após a vitória do candidato apoiado e com base na estratégia de divulgação de informações falsas, foi criado um departamento que recebeu a incumbência de propagar fake news sobre os mais variados temas que envolviam os seus opositores e as instituições públicas.

Hoje, ele é conhecido e investigado como "Gabinete do Ódio", pois virou foco no inquérito que tramita no STF sob número 4781/DF, de 2019 e em uma CPI no Congresso Nacional. Depois de denúncias de parlamentares e coletâneas de provas, o inquérito culminou em indiciados e na tentativa de desmantelar essa organização fundada em fake news que tinha o objetivo de obter vantagem política e econômica.

Após as eleições, este gabinete passou a agir contra a honra das instituições com o intuito de num futuro próximo alterá-las ao seu bel prazer, interferindo no Estado Democrático de Direito ao incitar o desmanche de instituições políticas e judiciárias criadas pela Constituição Federal de 1988, que democraticamente conquistadas em favor da coletividade.

\footnotetext{
${ }^{4}$ Empresários bancam campanha contra o PT pelo Whatsapp. Disponível em: $<$ https://www1.folha.uol.com.br/poder/2018/10/empresarios-bancam-campanha-contr a-o-pt-pe lo-what sapp.shtml> Acessado em 05.08.2020
} 
Em uma democracia, o povo é o detentor do direito de eleger, legislar e opinar, tendo como foco a defesa dos direitos fundamentais como o da liberdade, da igualdade e da dignidade da pessoa humana. Assim, se a democracia se traduz nas palavras "liberdade" e "respeito", é necessário falar da disseminação de fake news dentro da democracia, pois esse mecanismo afeta as liberdades e, na maioria das vezes, prejudica a própria ideia de verdade a longo prazo, podendo mudar os rumos da política para sempre.

Assim, o que se viu desde as eleições de 2018, foi a propagação de notícias falsas com o intuito de macular a imagem de pessoas públicas, bem como, a idoneidade de instituições sociais. Dito isso, por meio de documentos oficiais de departamentos públicos e documentos públicos do inquérito número 4781 do Supremo Tribunal Federal e opiniões de alguns escritores especializados no tema, este artigo visa abordar uma breve reflexão sobre o poder de influência da mídia (especialmente das redes sociais) dentro do Estado Democrático e como pode se evitar que injustiças aconteçam pelo desrespeito aos preceitos de nossa democracia nacional.

\section{Fake news no Brasil}

O termo fake news, neste objeto de estudo, tem como um dos principais significados, uma notícia falsa que traz algum benefício político ou econômico a alguém, desde que altamente compartilhada. O processo baseado em dados computacionais propaga uma mensagem falsa para o maior número de pessoas e é compartilhado por sites fakes, robôs e outros interessados, culminando em uma notoriedade paradoxal. A notícia falsa tem o fito de fornecer vantagem política ou econômica desinformando (BRAGA, 2018).

O conteúdo tem que ter potencial e ser relevante, principalmente quando a notícia é algo desejado como, por exemplo, considerando o ódio da população após escândalos de corrupção em 2018, tornou-se popular a notícia que vinculava o candidato Fernando Haddad com o kit gay, que teoricamente sexualizaria crianças nas escolas. $\mathrm{O}$ fato ocorreu em meados de setembro de 2018 e teve até participação do então presidenciável Jair Bolsonaro, que tocava neste assunto com indignação em vídeos de campanha.

O TSE ordenou à época que, por se tratar de "desinformação", o conteúdo relacionado a Haddad fosse tirado das redes, porém, já havia sido grandemente compartilhado prejudicando o debate político ${ }^{5}$, visto que se tratava de uma notícia muito alarmante e prejudicial. Nenhum

\footnotetext{
${ }^{5}$ Horbach, Carlos, Ministro do Tribunal Superior Eleitoral em decisão nos autos da Representação No060169941.2018.6.00.0000 - CLASSE 11541 BRASÍLIA.DISTRITO FEDERAL. <https://pje.tse.jus.br:8443/pjeweb/Processo/ConsultaDocumento/listView.seam?x=18101523562 $869600000000531558>$. Acesso em 05-082020.
} 
espaço expressou tanto os extremos das eleições de 2018 como as redes sociais. Jean-Philip Struck menciona no jornal internacional alemão DW Made for Minds, que com a expansão do acesso à internet e a política fundada atualmente nela, se multiplicaram os casos de fake news para impulsionar candidaturas e prejudicar candidatos opostos obtendo-se a vantagem da preferência (STRUCK, 2018).

Não obstante, a mídia jornalística brasileira sofreu com a disposição exacerbada de notícias falsas desde o período pré-eleitoral em 2018, pois não é possível frear diretamente os efeitos de algo que em segundos já atingiu a leitura de milhões de pessoas "viciando" suas compreensões políticas. Laura Chinchila, esteve no Brasil em 2018 como chefe da missão de observação eleitoral da Organização de Estados Americanos (OEA) e afirmou que a propagação de notícias falsas foi uma constante nos processos pré-eleitorais no Brasil e estendeu-se no dia das votações. Ainda, que não exista precedentes em estados democráticos para o uso massivo do Whatsapp como ferramenta para campanha eleitoral, este aplicativo influenciou sobremaneira o resultado das urnas em nosso país (CHINCHILLA, 2018).

Um marco histórico de 2018, na corrida presidencial foi a notícia publicada pelo Jornal "Folha de São Paulo", apontando um esquema de produção massiva de fake news a favor de um candidato. A notícia trouxe à tona umas das primeiras visões que teríamos sobre o já conhecido "Gabinete do Ódio", que foi posteriormente investigado em uma série de processos judiciais e administrativos.

Não apenas a Folha de São Paulo, mas também o Jornal "O Globo"7 e a BBC, de Londres, são citados em documento oficial da Procuradoria da República. A procuradora Geral da República e Procuradora-Geral Eleitoral à época, Raquel Dodge pediu à Polícia Federal por meio do ofício $\mathrm{n}^{\circ} 934 / 2018 / \mathrm{GAB} / \mathrm{PGR}^{8}$ que apurasse se empresas de tecnologia disseminaram, de "forma estruturada", informações falsas que atingiram os dois candidatos mais notáveis no momento eleitoral. No documento, Raquel Dodge informa que os fatos mencionados em reportagens jornalísticas motivaram a abertura de procedimento apuratório pela ProcuradoriaGeral Eleitoral (PGE). Destaca ainda que o objetivo é verificar a existência de eventual utilização de esquema profissional por parte das campanhas, com o propósito de propagar notícias falsas.

\footnotetext{
${ }^{6}$ Empresários bancam campanha contra o PT pelo Whatsapp. Disponível em: <https://www1.folha.uol.com.br/poder/2018/10/empresarios-bancam-campanha-contr a-o-pt-pe lo-what sapp.shtml> Acessado em 05.08.2020

${ }^{7}$ Agência ofereceu 80 milhões de disparos ilegais pelo whatsapp. Disponível em:

$<$ https://oglobo.globo.com/brasil/ao-psdb-agencia-ofereceu-80-milhoes-de-disparos-ilegais-pelo-whatsapp23167620>. Acessado em 05.08.2020.

${ }^{8}$ Ofício n934/2018/GAB/PGR. https://www.conjur.com.br/dl/raquel-dodge-pf-abra-inquerito-esquema.pdf
} 
Por seu turno, o Ministro da Segurança Pública, Raul Jungmann, ao receber o ofício citado, determinou a instauração da investigação pela $\mathrm{PF}^{9}$ e uma investigação paralela do Tribunal Superior Eleitoral também passou a existir.

Todos esses fatos ocorreram durante o primeiro turno das eleições. Com o início das investigações, ocorreu um debate político sobre fraudes nas urnas. O Tribunal Superior Eleitoral (TSE) teve que interferir novamente, desta vez para desmentir notícias fraudulentas que ofenderam a integridade coletiva e os princípios democráticos quanto ao processo de contagem dos votos pelo sistema de urnas. Em nota de esclarecimento ${ }^{10}$, declarou-se que o primeiro turno da eleição de 2018 foi realizada com lisura e que o TSE valoriza, sobremaneira, a maior conquista democrática no Brasil, as eleições diretas.

Não obstante, durante o processo eleitoral, foram criados alguns grupos de verificação de notícias falsas, um deles é o Comprova ${ }^{11}$, que trouxe à tona muitas inverdades largamente disseminadas nas redes sociais e se solidificou sendo hoje formado por uma coalisão de 33 veiculos de informação. O site do Comprova informa que já publicou 520 verificações de conteúdos de grande repercussão desde o início das atividades, em meados de 2018. Essas reportagens, multiplicadas pelos membros da coalizão, se transformaram em milhares de publicações veiculadas em TVs, rádios, jornais, sites de internet e em plataformas de redes sociais.

Destarte, é importante levantar o fato que as fake news ficaram conhecidas num ataque ao processo eleitoral em si, quando dois policiais militares publicaram um vídeo que viralizou, apontando fraudes na eleição de 2018. Uma atitude que questionou a veracidade e a honestidade do processo eleitoral como um todo. Vale salientar que o processo eleitoral é um símbolo democrático, e a disseminação de notícias fraudulentas imputando ilegalidade é preocupante. O Ministério Público do Distrito Federal e Territórios (MPDFT) publicou nota informando da abertura de processo criminal contra os policiais por promover uma desordem que prejudica os trabalhos eleitorais, algo tipificado como crime pelo artigo 296 do Código Eleitoral. O MPDFT afirmou que os fatos não podem ser descontextualizados, pois algumas das mensagens vinculadas ao vídeo orientava eleitores a gravar o momento da votação, o que é ilícito ${ }^{12}$.

\footnotetext{
${ }^{9} \mathrm{PF}$ instaura inquérito para investigar mensagens no whatsapp sobre presidenciáveis. Disponívelem: <https://politica.estadao.com.br/blogs/coluna-do-estadao/pf-instaura -inquerito-para -investigarmensagens-no-whatsapp-sobre-presidenciaveis/>. Acesso em 06.08.2020.

${ }^{10}$ Nota de esclarecimento do TSE. Disponível em: <http://www.tse.jus.br/imprensa/noticiastse/2020/Marco/nota-de-esclarecimento-do-tribunal-superior-eleitoral>. Acessado em 06.08.2020.

${ }^{11}$ Projeto Comprova. Disponível em:< https://projetocomprova.com.br/arquivos/> Acessado em 05.08.2020.

${ }^{12}$ Nota do MPDF sobre vídeo falso de policiais militares https://www.mpdf t.mp.br/por tal/index.php/comunicacao-menu/sala-de-imprensa/noticias/noticias-2019/10548-mpdft-considera-crimeeleitoral-atuacao-de-dois-pms-no-primeiro-turno-da-eleicao
} 
Em meio a tantas notícias falsas que vimos e que depois foram publicamente discutidas: uma que surpreende é a criação de link falso do Ibope grandemente disseminado via Whatsapp em outubro de 2018, que direcionava para uma página de pesquisa e depois sugeria o compartilhamento da mensagem. O link falso associado supostamente ao Ibope causou um efeito manada, ou seja, levou muitas pessoas a serem influenciadas no momento da decisão do voto. O Instituto Brasileiro de Opinião Pública e Estatística - IBOPE, emitiu uma nota para esclarecer que não realizou pesquisa via aplicativo de mensagens ${ }^{13}$. Obviamente, a nota oficial do Instituto não foi difundida como a fake news que gerou tanta indignação.

Após todo esse caos midiático brevemente explanado, foi eleito para presidente do Brasil, por vias democráticas, o candidato que mais refletiu a indignação das pessoas com o estado de coisas vivíamos à época. Frente a tantas adversidades econômicas e ao caos investigativo gerado pela operação Lava-Jato foi eleito uma figura caricata e representativa da indignação e da raiva sentida pela maioria. Todavia, de posse desse sentimento, engenheiros da discórdia com inteligência computacional mudaram as regras e os preceitos do jogo democrático quando perceberam o acesso a milhões de mentes facilmente persuadidas por chamadas de notícias que nem precisariam ser escritas ou fundamentadas. Bastava um áudio de Whatsapp com "ares de verdade" (DA EMPOLI, 2019).

Sendo assim, as fake news foram no Brasil alimentadas de emoções negativas, que garantiram maior participação popular ao cultivar a cólera de cada umm sem se preocupar com a coerência do coletivo. O algoritmo dilui as antigas barreiras ideológicas e rearticulou o conflito político tendo como base a falsa superação da oposição entre o "povo" e as "elites" (DA EMPOLI, 2019).

Em março de 2019, foi iniciado o Inquérito das Fake News no Supremo Tribunal Federal, dando ênfase à investigação sobre o "Gabinete do Ódio". Além disso, muitos processos no $\operatorname{TSE}^{14}$ foram abertos objetivando a cassação da chapa Jair Bolsonaro-Hamilton Mourão, com suspeitas de disparos de fake news no Whatsapp que pejoravam seus adversários políticos durante as eleições.

No Congresso Nacional, em meados de julho de 2019, instaurou-se uma comissão parlamentar de Inquérito sobre as fake news. A Comissão solicitou acesso aos IP's (internet

\footnotetext{
${ }^{13}$ Nota do IBOPE sobre link falso de pesquisa eleitoral. Dispnível em:<https://www.ib opeinteligencia.com/noticias-e-pesquisas/ibope-inteligencia-nao-realiza-pesquisa-eleitoral-pelo-whatsapp-ouemail/> Acessado em 06.08.2020

${ }^{14}$ Presidente do TSE instaura procedimento para averiguar uso de notícias falsas na internet. Disponível em: $<$ http://www.tse.ju s.br/impre nsa/no ticias-tse/2018/Marco/presidente-do-tse-instaura-procedimento-paraaveriguar-uso-de-noticias-falsas-na-internet. Acessado em 05.08.2020.
} 
protocols, que é o endereço dos computadores na internet) dos computadores deste Gabinete de três servidores ligados à presidência que produziam relatos diários sobre fatos do Brasil e do Mundo (distorcendo-os e reinterpretando-os), bem como, eram responsáveis pelas redes sociais da Presidência da República. Esta investigação acabou por descobrir que havia dinheiro público bancando a disseminação de fake news a partir do Palácio do Planalto.

A CPI mista presidida pelo senador Ângelo Coronel (PSD-BA), teve 180 dias para investigar a criação de perfis falsos e ataques cibernéticos nas diversas redes sociais, com possível influência nas decisões dos votos no processo eleitoral de $2018^{15}$. Esta CPI, por ora, está em suspensão em virtude da CPI da pandemia.

Relacionada a investigação e a necessidade de coibir o fator fake news, surgiu a proposta de Lei das Fake News PL 2.630/2020, de autoria do senador Alessandro Vieira e dos deputados federais Felipe Rigoni e Tabata Amaral ${ }^{16}$. Segundo eles, a proposta visa desestimular a manipulação de informações e garantir mais autenticidade e integridade nas plataformas de redes sociais e foi votada no senado em meados de junho de 2020.

Assim sendo, pode-se dizer que a disseminação de notícias falsas em larga escala, foi se tornando um problema cada vez maior para nossa nação, pois passou da simples opinião em grupos privados de Whatsapp para a geração de perfis falsos cada vez mais replicados que nos levaram à uma posição frágil, a saber, a de incerteza diante da exacerbação da liberdade de expressão e da violação do Estado Democrático de Direito. Mas esta fragilidade também favoreceu um repensar importante: quais são os rumos que nossa democracia está tomando diante destas mudanças tão radicais? O que pode ser feito para que nossa democracia não seja destruída?

Mas o choque de realidade não foi capaz de superar essas fragilidades, pois os fatos foram piorando quando as investigações desmantelaram grupos de pessoas que atuavam diretamente junto ao Gabinete Presidencial. Esses grupos despendiam tempo e dinheiro público, para agir em favor de seus próprios interesses (BASTOS, 2020). Isso ficou claro quando em meados de 2020, ataques aos Ministros do STF e seus familiares foram feitos para desqualificar o trabalho que estes viam desempenhando contra as fake news. Nesse contexto, tais ataques direcionaram mormente os olhares à defesa da democracia. Neste ambiente de dúvida e de

\footnotetext{
${ }^{15}$ CPI das Fake News. Disponível em: <https://www12.senado.leg.br/no ticias/mat erias/2019/09/10/representantes-de-redes-sociais-serao-convocados-a-depor-em-cpi-das-fake-news $>$. Acessado em 05.08.2020.

${ }^{16}$ Proposta de Lei n. 2630 de 2020. Disponível em: <https://www25.senado.leg.br/web/ativ idade/materias//materia/141944>.Acessado em 05.08.2020.
} 
ofensa contra as instituições democráticas, novos inquéritos e CPIs são intensificados na defesa dos interesses públicos, republicanos e democráticos.

Assim, como se já não bastassem os desafios da CPI das Fake News, em 2020 e 2021 foram instaurados novos inquéritos e CPIs para investigar os problemas que o governo federal teve que enfrentar por ação, coação ou omissão, diante da pandemia da COVID-19. Esses desafios surgiram justamente porque o modus operandi do atual governo federal é demarcado pela constante isenção ou inação diante dos problemas sociais. O desejo da posse e da manutenção no poder parece eclipsar ou embaçar a compreensão da realidade, pois diante dos fatos ocorridos em função das fake News ou da Covid-19, o que mais se vê é apenas a preocupação com o status ocupado e não uma atenção para com o seu povo por ele eleito.

Dessa forma, vale lembrar a decisão de abertura do Inquérito 4781/DF, de 2019, do Relator Ministro Alexandre de Moraes, exposta em seu preâmbulo:

\begin{abstract}
O objeto deste inquérito, conforme despacho de 19 de março de 2019, é a investigação de notícias fraudulentas (fake news), falsas comunicações de crimes, denunciações caluniosas, ameaças e demais infrações revestidas de animus caluniandi, diffamandi ou injuriandi, que atingem a honorabilidade e a segurança do Supremo Tribunal Federal, de seus membros; bem como de seus familiares, quando houver relação com a dignidade dos Ministros, inclusive o vazamento de informações e documentos sigilosos, com o intuito de atribuir e/ou insinuar a prática de atos ilícitos por membros da Suprema Corte, por parte daqueles que tem o dever legal de preservar o sigilo; e a verificação da existência de esquemas de financiamento e divulgação em massa nas redes sociais, com o intuito de lesar ou expor a perigo de lesão a independência do Poder Judiciário e ao Estado de Direito".
\end{abstract}

O texto é do documento oficial ${ }^{17}$. Em abril de 2020, o Senado suspendeu as atividades e os prazos das comissões temporárias e mistas enquanto a pandemia da Covid-19 durar. Com isso, a CPI foi prorrogada por tempo indeterminado ${ }^{18}$.

De qualquer modo, Hyury Potter explica que a mentira está presente na política desde a Grécia Antiga, mas a forma como o espaço político lida com esse discurso mudou com o tempo e ele perdeu os meios para combater uma informação falsa (POTTER, 2018). Apesar deste grande desafio, parece que estamos no caminho de uma mudança no que entendemos por democracia. Assim, precisamos buscar formas de coibir abusos na livre informação, bem como, encontrarmos meios de garantir que todos tenham acesso às informações para melhor exercerem seus direitos de participação, de escolha e de liberdade.

\footnotetext{
${ }^{17}$ Decisão de abertura de Inquérito no âmbito do STF. Disponível em: <http://www.stf.jus.br/arquivo/cms/noticiaNoticiaStf/anexo/mandado27maio.pdf>. Acessado em 08.08.2020

${ }^{18}$ Senado suspende prazos de comissões mistas e CPI das Fake News é prorrogada. Disponível em> <https://www12.senado.leg.br/noticias/audios/2020/04/senado-suspende-prazos-de-comissoes-mistas-e-cpi-dasfake-news-e-prorrogada-por-tempo-indeterminado> Acessado em 07/11/2021.
} 


\section{Democracia no Brasil}

O regime democrático é uma forma do regime político, dentro de um sistema político. É como um governante chega ao poder. No regime democrático, o povo participa da formação e manutenção do poder do Estado, geralmente por meio das eleições (BARROSO; ARAUJO Jr., 2011, p. 224).

Na Constituição Federal da República Brasileira de 1988, no Artigo 1 se lê: "Todo poder emana do povo, que o exerce por meio de representantes eleitos e, diretamente, nos termos desta Constituição" ". Estas são definições simples que o cidadão comum pesquisa e compreende como democracia. Ainda, se entende por um controle das instituições para que a ordem social se mantenha íntegra, elevando o nível do Estado Democrático de Direito. Em se tratando de representatividade, o fator de influenciar votos sempre foi utilizado nas campanhas e depende de investimento financeiro.

A última normalização do Tribunal Eleitoral recentemente vetou o financiamento de campanhas por empresas particulares. Desafortunadamente, este impedimento se mostrou interessante para a criação do sistema de fake News, pois esta ação acabou por facilitar a criação de um novo método de propaganda muito mais barato, de grande abrangência e possível de ser replicado por não humanos programados. Ainda que a legislação determine a declaração de gastos de campanha, inclusive os de impulsionamento, os investimentos em big-data não ficam transparentes aos cidadãos, pois não se sabe ao certo o quanto eles contribuíram com o fornecimento de seus dados pessoais e isso pode ter ocorrido dentro de uma ordem de grandeza muito substancial (CALDAS; CALDAS, 2019). O dilema maior apresenta-se quando uma parcela considerável de cidadãos, considerados analfabetos digitais, faz $\mathrm{o}$ trabalho "involuntário" de promover e divulgar informações falsas.

Outrossim, para atingir milhões de pessoas, é necessário obter os dados delas, tornandoas foco de notícias falsas para influenciá-las com facilidade. Pessoas que estão indecisas ou pessoas que estão grandemente indignadas são alvo fácil deste tipo de manipulação. Assim, tudo que elas postam e compartilham é coletado por um grande sistema para direcionar à elas as notícias que elas gostariam que fosse verdade mas comumente não são.

Nas últimas décadas, as instituições brasileiras voltadas à repressão de crimes têm dado mostra de sua incapacidade em operar adequadamente dentro de um cenário permeado por inovações tecnológicas que envolvem, dentre outras novidades, sistemas eletrônicos de

\footnotetext{
${ }^{19}$ Constituição da República. Disponível em <http://www.planalto.gov.br/ccivil_03/constituicao/constituicao.htm>. Acessado em 05.08.2020
} 
armazenamento e transmissão de informações. Tais episódios ilustram como uma nova realidade demanda, por parte do Poder Judiciário, novos conhecimentos e estratégias (CALDAS; CALDAS, 2019).

$\mathrm{Na}$ verdade, houve uma modificação nas atitudes e no comportamento dos brasileiros em relação à política, fruto de um conjunto de fatores (o mercado, a globalização, a informática, dentre outros), porém, na essência, os brasileiros continuam a desacreditar nas instituições que constituem o pilar da democracia representativa (CALDAS; CALDAS, 2019). Infelizmente, sempre houve uma tendência não participativa dos cidadãos em nosso país, pois muitos preferem a inércia. Todavia, nos últimos anos esse sentimento ficou mais cristalizado devido aos grandes escândalos de corrupção investigados pela Operação Lava-Jato e outras investigações que temos notícia como as CPI’s que se tornaram foco da mídia, processos que até então, não tinham tanta notoriedade antes do advento acelerado das redes sociais e outras mídias.

Assim, pode-se dizer que, depois de conhecermos uma eleição baseada em publicidade eleitoral via internet e big data, a política seguiria utilizando esses métodos comprovadamente eficazes. Mas não é o que se constata. Atualmente, o governo federal utiliza a mesma estratégia para fazer lobbying político. O que nos leva a afirmar que esta estratégia que, na velocidade da era da informação, já pode-se dizer antiga, está em pleno vigor.

Deste modo, o que se percebe da última eleição presidencial, é que o Brasil trabalha em várias frentes de análise política, seja de direita ou de esquerda, para coibir a disseminação de notícias que tragam a derrocada da democracia como a entendemos até agora buscando formas eficazes de encontrar as fontes online, de remover conteúdos impróprios contra o sistema democrático. Contudo, nesta luta, a estratégia das fake news parece prevalecer por entrar em rota de colisão com os princípios constitucionais preconizados na Carta Magna de 1988.

Não obstante, diante da avançada e célere era da informação, os métodos de controle e de garantias de direitos estão se tornando ponto de discussão intensa e causando grandes indignações sociais, pois este terreno parece ser “incontrolável”. A grande marcha hoje é pela manutenção da democracia, porém isto vêm afetando diretamente entendimentos sobre liberdade de expressão. As discussões de pontos que pareciam pacíficos para todos estão voltando a entrar em pauta pois ameaçam interesses de máquinas políticas poderosas.

\section{Os detentores da Democracia e o Inquérito das Fake News}

Pensa-se que uma democracia se consolida meramente pela sua capacidade de sobreviver a atentados contra sua institucionalidade. Contudo, a democracia moderna na qual o 
Brasil se transformou, trata de favorecer mais interesses privados do que públicos. Nesse sentido, parece que o amadurecimento de uma democracia pensada para fixar a igualdade e a representatividade putrefez-se em uma contínua individualização de interesses pautados em processos judiciais intermináveis e em legislações específicas para grupos econômicos que drenam verbas para setores que não representam o grande coletivo ou "minorias".

Esses grupos interessados em exclusão de minorias e no favorecimento de teorias do ódio e da vingança contra legislações democráticas deram azo na atualidade aos inquéritos principiados pelo Supremo Tribunal Federal.

Mas alguém pode se perguntar: qual é a razão pela qual o STF está, ele mesmo, principiando inquéritos $?^{20}$ Como pode ele, como órgão julgador, detentor da definitiva interpretação da Constituição da República e protetor dessa, exercer a função de inquisitor e julgador? Pois sim, discutiu-se a viabilidade do procedimento e foi constatada a necessidade de se garantir os últimos resquícios de democracia pois o STF, nesse contexto, assumiu o papel de ser instrumento de proteção da ordem democrática como detentora da ordem constitucional.

Assim sendo, o inquérito das fake News está correndo como processo sigiloso, porém algumas decisões foram publicadas e detém conteúdo afeto à democracia. A decisão de 27 de maio de 2020, sobre pedido de liberação de mandado de busca e apreensão de equipamentos e de acesso a dados de perfis em empresas de armazenamento e custódia de dados, descreve que pelas provas constantes dos autos, restou clara a existência do chamado "Gabinete do ódio" creditada pelo relator como uma associação criminosa dedicada à disseminação de fake news, ataques ofensivos à diversas pessoas, às autoridades e às instituições, dentre elas, o Supremo Tribunal Federal com conteúdo de ódio, subversão da ordem e incentivo à quebra da normalidade institucional e democrática ${ }^{21}$.

Não discutimos sobre os acusados ou sobre as vítimas, mas sobre os atos citados que sobressaem e que ferem diretamente os direitos da coletividade. Houve publicações em redes sociais altamente divulgadas em favor da instauração do AI-5 ou procedimento análogo, utilizado no passado recente de nosso país pela ditadura militar. A decisão menciona nas folhas 07 a 10 da decisão que algumas publicações continham notícias mentirosas sobre ministros e sobre atentados ao Governo do atual presidente por parte do Supremo.

\footnotetext{
${ }^{20}$ Plenário conclui julgamento sobre a validade do inquérito sobre fake news e ataques ao STF. Disponível em: <http://portal.stf.jus.br/noticias/verNoticiaDetalhe.asp?idCo nteudo=445860\&ori=1 >. Acessado em 09.09.2020. ${ }^{21}$ Decisão sobre expedição de mandados de busca e apreensão nos autos do Inquérito. Disponível em:<http://www.stf.jus.br/arquivo/cms/noticiaNoticiaStf/anexo/mandado27maio.pdf>. Acessado em 09.08.2020.
} 
As notícias colocaram em perigo a independência dos poderes e do Estado Democrático de Direito. Isto porque o STF compreendeu que as referidas postagens atacaram diretamente o próprio sistema ao qual estamos submetidos pela Constituição da República. Além disso, a liberdade de expressão não pode afetar os direitos coletivos, o que, neste caso, ocorreu com a incitação às ofensivas por parte do atual presidente contra o Tribunal, o que atentou contra a Constituição Federal da República e contra a normalidade institucional e democrática.

Cita-se, ainda, que os ataques de notícias falsas e incitações de ódio ao Supremo Tribunal Federal buscaram desestabilizar a instituição e a independência dos poderes para, por último, tentar reimplantar um sistema antidemocrático como foi durante a ditadura militar.

Assim sendo, depois da decisão supra discutida, houve busca e apreensão de materiais de mídias contra os suspeitos. Novas descobertas foram feitas e foram delineados diversos pontos obscuros da investigação, dando veracidade aos fatos imputados ao agora popular "Gabinete do Ódio". Ainda, em meados de agosto de 2020, as contas dos envolvidos no processo relatado foram excluídas das redes.

No decorrer de 2021, segundo notícia vinculada pela revista Veja ${ }^{22}$, as ações do STF surtiram efeitos positivos, visto foram reduzidos em 75\%, os ataques ao Supremo Tribunal Federal. É evidente que isso não foi erradicado por completo, pois apesar disso, ainda houve episódios de ataques de grupos extremistas e ameaças de morte oriundas de pessoas influentes no país contra os ministros. O que, no fim das contas, não passou de um blefe, pois os discursos de ódio foram reduzidos.

O que se nota, é que os Ministros estão agindo rapidamente contra episódios de ódio nas redes sociais ${ }^{23}$, oriundos de parlamentares ou de cidadãos comuns. Isso pode ser verificado com o caso recente do deputado federal Daniel Silveira que divulgou um vídeo em tom de ameaça ao Ministro do Supremo Edson Fachin. No referido evento, o deputado foi preso em flagrante e o episódio parece ter surtido efeito no combate às ações extremistas contra a democracia e a estabilidade dos três poderes.

Daniel Silveira defendeu em vídeo a quebra do sistema democrático pela instituição do Ato Institucional AI-5 e a substituição dos integrantes do Supremo Tribunal Federal. A câmara dos Deputados rechaçou, em sua maioria, os comentários do parlamentar ${ }^{24}$. O que se depreende deste acontecimento é que há uma linha tênue entre liberdade de expressão e violência incitada por meio de palavras contra um sistema democrático, conquistado pelo povo e em nome do

\footnotetext{
${ }^{22}$ https://veja.abril.com.br/brasil/ataques-contra-o-stf-cairam-75-apos-inquerito-das-fake-news/

${ }^{23} \mathrm{https}: / / v e j a$ abril.com.br/politica/prisao-de-deputado-e-forte-sinal-de-reacao-das-instituicoes-ao-extremismo/

${ }^{24}$ https://www.camara.leg.br/noticias/729294-camara-decide-manter-prisao-do-deputado-daniel-silveira/
} 
povo. Vê-se, assim, que uma constante vigilância e atenção devem ser dispensadas para que a nossa frágil e inalienável liberdade seja garantida. Para tanto, se faz necessário um olhar atento e crítico diante do mundo, hoje fortemente influenciado pelo poder da mídia e das redes sociais.

\section{Considerações finais}

No início da construção deste artigo, pensava-se no quão absurdo é a atual realidade que estamos vivendo: eleições proclamadas pela influência de atos robóticos, processos judiciais de ordem anticonstitucional tomaram a atenção frente a tantas demandas urgentes neste país e o desrespeito contra a democracia se notabilizou. Mas parece que estamos acostumados e anestesiados diante de tantos descalabros

Em nosso entendimento, as fake news são sombras dentro da caverna, mas que podem assumir o papel de ser o verdadeiro conhecimento do mundo, caso não sejam reprimidas com a justiça e a busca da verdade. O quadro de interferência na opinião dos eleitores, por meio de eventuais fake news, representa uma "afronta" à integridade do processo eleitoral, o que afeta diretamente o Estado Democrático de Direito.

Dentro dos acontecimentos envolvendo as fake news no Brasil desde 2018 e como estamos tratando o avanço desse problema no país, a maior percepção é a de que necessitamos encontrar um meio de suprimir a disseminação de notícias fraudulentas que atentam contra a liberdade de expressão e a democracia, antes que a segurança de nossas bases democráticas se dissipem.

De acordo com Toffoli: "O regime democrático pressupõe um ambiente de livre trânsito de ideias, no qual todos tenham direito à voz. A democracia somente se firma e progride em um ambiente em que diferentes convicções são expostas e discutidas em um debate rico, plural e resolutivo" ${ }^{25}$. Veja que a exposição massiva a notícias falsas não eleva o debate, apenas afunda o coletivo em mentiras, sem fundamento, que buscam atingir pessoas indecisas e gerar indignação contra o sistema vigente, contribuindo para uma situação de caos que favorece alguém que quer liderança e poder acima das liberdades do povo. A democracia que vivemos deve ter outra primazia: a liberdade com debate e com decisões conjuntas calcadas em uma ordem democrática e constitucional.

Conforme afirmou Hannah Arendt, em uma entrevista de 1974: "Se todo mundo sempre mentir para você, a consequência não é que você vai acreditar em mentiras, mas sobretudo que

\footnotetext{
${ }^{25} \mathrm{https}: / /$ www.nsctotal.com.br/noticias/ministro-do-stf-dias-toffoli-derruba-censura-a-livros-na-bienal-do-rio-dejaneiro
} 
ninguém passe a acreditar mais em nada" 26 . Assim, de modo derradeiro, é preciso estudar maneiras positivadas de controle à expansividade das mídias sociais de modo a identificar os interlocutores de má índole, possibilitando a livre e idônea expressão de todos aqueles que respeitam a Constituição Federal e o Estado Democrático de Direito.

\section{Referências}

Agência ofereceu 80 milhões de disparos ilegais pelo whatsapp. Disponível em: <https://oglobo.globo.com/brasil/ao-psdb-agencia-ofere ceu-80-milhoes-de-disparosilegais-pelo-whatsapp-23167620>. Acessado em 05.08.2020.

BAPTISTA, Carla. Digitalização, desinformação e notícias falsas. In: FIGUEIRA João, SANTOS Silvio (Org.). As Fake News e a nova ordem (des) informativa na era da pós-verdade. Coimbra: Imprensa da Universidade de Coimbra, Setembro 2019;

BARROSO, Darlan, ARAUJO JR., Marcos Antonio. Direito Constitucional. Revista dos Tribunais. 11 edição. São Paulo, 2011.

Base de datos de Misiones de Observación Electoral y Recomendaciones. Reporte preliminar. Disponível em: $<\mathrm{http}: / / \mathrm{www}$ oas.org/eomdatabase/Mo eRep ort.aspx? Lang=es\&Id=410\&MissionId=489. Acessado em 05.08.2020.

BASTOS, Gustavo. O Gabinete do Ódio. A Ação do Facebook desarticulou um grupo que envolve assessores e funcionários de gabinetes políticos. Disponível em<https://www.seculodiario.com.br/colunas/o-gabinete-do-odio>. Acessado em 08.05.2020;

BRAGA, Renê Morais da Costa. A indústria das fake news e o discurso de ódio. In: PEREIRA, Rodolfo Viana (Org.). Direitos políticos, liberdade de expressão e discurso de ódio: volume I. Belo Horizonte: Instituto para o Desenvolvimento Democrático, 2018. p. 203-220

CALDAS, Camilo Onoda Luiz. CALDAS Pedro Neris Luiz. Estado, democracia e tecnologia: conflitos políticos e vulnerabilidade no contexto do big-data, das fake news e das shitstorms. Perspect. ciênc. inf. vol.24 no.2 Belo Horizonte Apr./June 2019 Epub Sep 02, 2019

Constituição $\quad$ da $\quad$ República. $\quad$ Disponível em <http://www.planalto.gov.br/ccivil_03/constituicao/constituicao.htm>. Acessado em 05.08 .2020

CPI das Fake News. Disponível em: <https://www12.senado.leg.br/no ticias/mat erias/2019/09/10/representantes-de-redes-sociais-serao-convocados-a-depor-em-cpi-das-fakenews>. Acessado em 05.08.2020.

\footnotetext{
26 https://www.migalhas.com.br/quentes/311850/ministro-toffoli-destaca-importancia-do-combate-as-noticiasfraudulentas-em-seminario-na-camara
} 


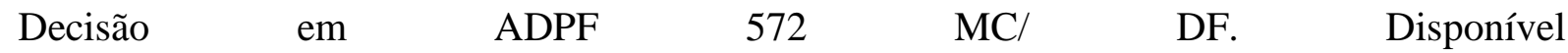
em: $<$ http://www.stf.jus.br/arquivo/cms/noticiaNoticiaStf/anexo/ADPF572VotoDT.pdf $>$.Aces sado em 10.08.2020.

Decisão sobre expedição de mandados de busca e apreensão nos autos do Inquérito. Disponível em:<http://www.stf.jus.br/arquivo/cms/noticiaN oticiaStf/ anexo /mandado27maio.pdf $>$. Acessado em 09.08.2020.

Declaração conjunta sobre liberdade de expressão e "fake news", desinformação e propaganda. Organização dos Estados http://www.oas.org/es/cidh/expresion/showarticle.asp?artID=1056\&lID=2

Empresários bancam campanha contra o PT pelo whatssap $<$ https://www1.folha.uol.com.br/poder/2018/10/empresarios-bancam-campanha-contra-o-ptpelo-whatsapp.shtml> acessado em 05-08-2020.

Horbach, Carlos, Ministro do Tribunal Superior Eleitoral em decisão nos autos da $\begin{array}{lllll}\text { Representação } & N^{\circ} 0601699-41.2018 .6 .00 .0000 & - & \text { CLASSE } & 11541\end{array}$ BRASÍLIA.DISTRITOFEDERAL.<https://pje.tse.jus.br:8443/pjeweb/Processo/ConsultaDocumento/listView.seam? $\mathrm{x}=18101523562869600000000531558>$.A cesso em 05-08-2020.

Nota de esclarecimento do TSE. Disponível em: <http://www.tse.jus.br/imprensa/noticiastse/2020/Marco/nota-de-esclarecimento-do-tribunal-superior-eleitoral>. Acessado em 06.08.2020.

Nota do IBOPE sobre link falso de pesquisa eleitoral. Dispnível em:<https://www.ib opeinteligencia.com/noticias-e-pesquisas/ibope-inteligencia-nao-realiza-pesquisa-eleitoralpelo-whatsapp-ou-email/> Acessado em 06.08.2020

Nota do MPDF sobre vídeo falso de policiais militares. https://www.mpdf t.mp.br/portal/index.php/comunicacao-menu/sala-de-imprensa/noticias/noticias-2019/10548mpdft-considera-crime-eleitoral-atuacao-de-dois-pms-no-primeiro-turno-da-eleicao

PF instaura inquérito para investigar mensagens no whatsapp sobre presidenciáveis. Disponível em: <https://politica.estadao.com.br/blogs/co luna-do-estadao/pf-instaura-inquerito-parainvestigar-mensagens-no-whatsapp-sobre-presidenciaveis/>. Acessado em 06.08.2020.

Plenário conclui julgamento sobre a validade do inquérito sobre fake news e ataques ao STF. Disponível em: <http://portal.stf.j us.br/noti cias/verNo ticiaDetalhe.asp?idCo nteudo $=445860 \&$ ori $=1>$. Acessado em 09.09.2020.

POTTER, Hyury, A mentira é tão velha quanto a política, mas ganhou novos meios. Disponivel em: $\langle$ https://p.dw.com/p/37BfX>. Acesso em 05/08/2020.

Presidente do TSE instaura procedimento para averiguar uso de notícias falsas na internet. Disponível em:<http://www.tse.ju s.br/imprensa/no ticias-tse/2018/Marco/presidente-do-tseinstaura-procedimento-para-averiguar-uso-de-noticias-falsas-na-internet. Acessado em 05.08.2020. 
Programa de verificação de fake news do CNJ. Disponível em: $<$ https://www.cnj.jus.br/programas-e-acoes/painel-de-checagem-de-fake-news/>. Acessado em 10.08.2020.

Projeto Comprova. Disponível em: $<$ https://projetocomprova.com.br/arquivos/> Acessado em 05.08.2020.

Proposta de Lei n. 2630 de 2020. Disponível em: <https://www25.senado.leg.br/web/atividade/materias/-/materia/141944> .Acessado em 05.08.2020.

STRUCK, Jean-Philip. A eleição que transformou a política brasileira. Disponível em:< https://p.dw.com/p/37HpR>.Acesso em 05-08-2020. 